\title{
EFEKTIVITAS MICROSOFT TEAMS TERHADAP HASIL PEMBELAJARAN IPA PADA MASA PANDEMI COVID-19
}

\author{
Titiek Yusfriyanti \\ SMP Negeri 44 Surabaya \\ titiekyusfriyanti@gmail.com
}

\begin{abstract}
Abstrak
Microsoft Teams sebagai salah satu platform pembelajaran yang memungkinkan guru dan siswa untuk berkolaorasi dan berinteraksi selama pembelajaran secara daring (online). Penelitian ini bertujuan untuk mengetahui efektivitas penerapan Microsoft Teams sebagai platform pembelajaran pada masa pandemi Covid-19 di SMP Negeri 44 Surabaya. Metode yang digunakan dalam penelitian ini adalah kuantitatif yang dianalisis dalam bentuk statistik. Berdasarkan data yang diperoleh menunjukkan ahwa penggunaan Microsoft Teams terdiri dari tiga indikator yaitu kemudahan akses Microsoft Teams yang menghasilkan nilai presentasi 80.5, pemahaman materi pemelajaran menggunakan Microsoft Team memberikan skor nilai presentasi 82 dan keunggulan saat menggunakan Microsoft Teams. Hasil nilai yang disajikan adalah 78. Dari ketiga indikator terseut memiliki persentase total rata-rata $80.16 \%$ yang dikatakan efektif digunakan dalam pembelajaran IPA. Untuk efektivitas penggunaan Microsoft Teams dalam pembelajaran adalah tepat untuk tujuan tersebut dan Microsoft Teams secara signifikan mempengaruhi hasil pembelajaran siswa kelas 9F di SMP Negeri 44 Surabaya pada tahun akademik 2020/2021.
\end{abstract}

Kata Kunci: efektifitas, pembelajaran daring, pandemic, IPA

\begin{abstract}
Microsoft Teams as a learning platform that allows teachers and students to collaborate and interact during online learning. This study aims to determine the effectiveness of implementing Microsoft Teams as a learning platform during the Covid-19 pandemic at SMP Negeri 44 Surabaya. The method used in this research was quantitative which was analyzed in statistical form. Based on the data obtained, it showed that the use of Microsoft Teams consists of three indicators, namely the ease of access to Microsoft Teams which results in a presentation value of 80.5, understanding of learning material using Microsoft Teams gives a presentation score of 82 and excellence when using Microsoft Teams. The result of the value presented was 78. Of the three indicators, the average total percentage is $80.16 \%$ which is said to be effectively used in Science learning (IPA). For the effectiveness of using Microsoft Teams in learning,
\end{abstract}


Efektifitas Microsoft Teams ...

it is appropriate for this purpose and Microsoft Teams significantly affects the learning outcomes of grade $9 F$ students at SMP Negeri 44 Surabaya in the 2020/2021 academic year.

Keywords: efectiveness, online learning, pandemic, IPA

\section{PENDAHULUAN}

Penyebaran Coronavirus Disease 2019 (Covid-19) menjadi penyebab angka kematian yang paling tinggi untuk saat ini (Rachmat dan Krisnadi 2020). Dampak pandemi Covid-19 yang melanda dunia, termasuk Indonesia, telah mengubah tatanan kehidupan terutama dalam sektor pendidikan. Selain terjadi penutupan sejumlah fasilitas publik, semua lembaga pendidikan terutama sekolah dan perguruan tinggi dipaksa untuk menunda aktivitas pembelajaran secara tatap muka (Hasanah et al., 2020). Sampai awal 2021, proses pembelajaran yang dilakukan di Indonesia masih berbasis online karena cara ini dinilai cukup efektif dalam meminimalisasi penyebaran Covid-19. Kondisi ini ditunjang oleh kemajuan teknologi yang pesat yang penting untuk menunjang proses pembelajaran di berbagai jenjang pendidikan. Namun demikian, para guru memerlukan kesiapan.

Pemerintah Indonesia memberikan edaran dan mengkonfirmasikan adanya kasus Covid-19 pertama kalinya yaitu pada tanggal 02 Maret 2020 (Wahyono, 2020). Sehingga pemerintah melakukan Langkah tegas untuk memutus rantai penyebaran Covid-19. Adanya Covid-19 menimbulkan pengaruh yang tidak sehat pada berbagai sektor yang ada salah satunya adalah pada bidang pendidikan, di mana pembelajaran pada mulanya dilakukan secara langsung tetapi saat ini pembelajaran harus dilaksanakan secara daring atau online. Oleh karena itu, edaran dari Siaran Pers Nomor: 137/sipres/A6/VI/2020 pada 15/07/2020 tentang penyelenggaraan pembelajaran yang akan dilaksanakan pada tahun akademik baru terkhususnya di masa pandemi: daerah berstatuskan kuning, oranye dan merah maka tidak melaksanakan kegiatan belajar secara langsung (Kemendikbud, 2020) serta diikuti dengan pemberitahuan atau himbauan yang diperoleh dari masingmasing institusi pendidikan tersebut berada.

Adanya peraturan yang dikeluarkan tersebut, maka pembelajaran 
yang biasanya dilakukan secara tatap muka dirubah untuk melakukan aktivitas pembelajaran dari rumah masing-masing yang dikenal dengan stay at home, yang di Indonesia sendiri diberlakukan secara bersamaan pada bulan Maret 2020. Oleh karena itu, setiap instansi bisa memanfaatkan teknologi untuk melakukan pembelajaran secara daring atau yang dikenal sebagai e-learning. E-learning dapat dikatakan suatu media pembelajaran dikarenakan memanfaatkan internet, yang bertujuan untuk memberikan solusi dan dapat meningkatkan pengetahuan dan keterampilan pada seseorang (Sabran \& Sabara, 2019). Oleh karena itu, dengan adanya e-learning dapat membantu untuk menyampaikan pembelajaran yang tidak diajarkan secara langsung oleh tenaga pendidik.

Secara umum, pembelajaran secara online dipahami sebagai pembelajaran jarak jauh dengan memakai teknologi informasi seperti laptop dan gawai (handphone) antara siswa dan guru maupun antara mahasiswa dengan dosen sehingga kegiatan belajar mengajar bisa berjalan dengan sebagaimana mestinya. Pembelajaran yang berlangsung tanpa adanya tatap muka. Siswa dan guru bisa mengakses materi dan saling berinteraksi kapanpun dan dimanapun tanpa terikat oleh waktu dan sekat geografis. Di samping itu, selama pandemi Covid-19, pemahaman guru terkait penggunaan teknologi dalam pembelajaran ikut meningkat sehingga mampu menjawab tantangan dalam masa sekarang ini. Tantangan tersebut yaitu, guru diharapkan mempunyai kreativitas tinggi dalam pengintegrasian pembelajaran dengan teknologi supaya tujuan pembelajaran dapat dicapai secara efektif.

Pembelajaran secara daring (online) menjadi bentuk solusi dalam mengatasi pembelajaran saat ini dimana pembelajaran tatap muka pada kondisi Covid-19 seperti saat ini. Hal ini menuntut semua stakeholder Pendidikan mampu beradaptasi dengan keadaan yang ada, termasuk halnya dalam proses pembelajaran. Pembelajaran jarak jauh menjadi tantangan tersendiri bagi para guru khususnya guru Ilmu Pengetahuan Alam (IPA). Untuk dapat beradaptasi dengan situasi pandemi, kemampuan teknologi sangat penting dimiliki oleh pendidik. Mengharuskan pendidik mempelajari dan mengeksplor media teknologi berbasis aplikasi yang tepat 
untuk digunakan dalam proses kekurangan pembelajaran jarak jauh yaitu pembelajaran, seperti media chatting, pengawasan peserta didik oleh guru lebih video conference dan lain-lain. sulit dilakukan, pemahaman materi oleh Pemanfaatan teknologi digital dalam siswa cenderung rendah karena rendahnya proses pembelajaran memungkinkan guru interaksi antara peserta didik dan guru, dan dan peserta didik berada di tempat yang berbeda. Hal ini berarti dalam pembelajaran daring sangat dibutuhkan Teknologi Pendidikan (Indarwati, 2021). Teknologi sendiri dari masa ke masa selalu mengalami perkembangan dan semakin banyak memberikan peluang baru dalam membantu manusia agar dapat berinteraksi dengan mudah bahkan teknologi sangat membantu dalam proses pembelajaran, aspek pedagogic dan meteri yang disajikan dalam bentuk konten-konten yang menarik merupakan bentuk pemanfaatan teknologi saat ini (Novianti, Fatkhia, \& Nuryana, 2020).

Pembelajaran jarak jauh tetap diupayakan oleh guru agar pembelajaran tetap berlangsung seperti biasanya. Pembelajaran jarak jauh memiliki kelebihan dan kekurangan. Kelebihan pembelajaran jarak jauh antara lain akses yang tidak terbatas ruang dan waktu, biaya yang terjangkau, dan dapat mendorong peserta didik untuk lebih berpikir kritis (Pangondian, dkk., 2019). Adapun tidak semua siswa memiliki handphone (Nengrum et al., 2021). Perkembangan teknologi informasi dan komunikasi memberikan kontribusi yang sangat besar dalam pelaksanaan pembelajaran jarak jauh. Menurut teknologi informasi dan komunikasi berperan sebagai sarana pembelajaran jarak jauh atau lazim dikenal dengan istilah platform pembelajaran Google classroom, Google Meet, Zoom, Microsoft Teams merupakan beberapa contoh platform pembelajaran yang dapat dimanfaatkan dalam pembelajaran jarak jauh selama pandemic Covid-19.

\section{Microsoft Teams (Ms Teams)} merupakan salah satu platform pembelajaran yang memungkinkan guru dan peserta didik berkolaborasi maupun berinteraksi pada saat pembelajaran daring (Rakhmawati \& Sulistianingsih, 2020). Hal ini dikarenakan dalam platform Microsoft Teams terdapat fitur chatting dan learning vidio yang mudah digunakan. Kelebihan dari Microsoft Teams adalah mudah digunakan peserta didik, adanya 
fitur HD dan Audio dengan kualitas baik dan Microsoft Teams sangat menjaga privasi atau kerahasiaan penggunanya (Sulz, 2020). Microsoft teams adalah produk layanan berlangganan yang ditawarkan oleh Microsoft sebagai bagian dari lini produk Microsoft Office. Secara umum, fasilitas Microsoft 365 terdiri dari perangkat lunak Microsoft Office serta perangkat lunak berbasis komputasi awan sebagai produk layanan untuk lingkungan bisnis, seperti Hosting Exchange Server, Skype for Business Server, dan SharePoint ditambah opsi tambahan layanan Windows 10 Enterprise. Semua paket Microsoft 365 diperbarui otomatis tanpa biaya tambahan.

Menurut Pangondian, dkk., (2019), keberhasilan pelaksanaan pembelajaran jarak jauh dipengaruhi oleh tiga hal yaitu kesiapan teknologi, karakteristik pendidik dan karakteristik siswa. Di antara ketiga faktor penentu tersebut, karakteristik pendidik berperan utama dalam menentukan efektivitas pembelajaran jarak jauh. Peran utama tersebut terletak dalam penerapan instruksional pembelajaran berbasis teknologi yang digunakan. Oleh karenanya seorang pendidik (guru) dalam pembelajaran jarak jauh diharapkan selektif dalam memilih platform pembelajaran sesuai dengan kesiapan teknologi dan karakteristik siswa.

Berdasarkan hasil pengamatan kegiatan pembelajaran di SMP Negeri 44 Surabaya, diperoleh informasi bahwasanya platform pembelajaran yang digunakan adalah Microsofts Teams. Platform Microsofts Teams merupakan satusatunya platform pembelajaran yang digunakan semenjak adanya kebijakan pembelajaran jarak jauh dan telah berjalan selama hampir satu tahun pada masa pandemic Covid-19. Sehingga platform ini membuat ketertarikan tersendiri untuk penggunanya. Dikarenakan SMP Negeri 44 Surabaya hanya menggunakan Platform Microsofts Teams. Pada penelitian sebelumnya hanya meneliti tentang minat belajar peserta didik dengan menggunakan Microsofts Teams, tetapi hanya mengukur pada minat saja berbeda dengan penelitian ini. Penelitian ini yang pertama, mengukur efektivitas penggunaan Microsofts Teams dan yang kedua, mengukur pengaruh Microsofts Teams pada hasil belajar. Tujuan dari penelitian ini yaitu untuk mengetahui efektifitas Microsofts Teams dan pengaruh platform tersebut pada hasil pembelajaran IPA di SMP Neegeri 44 Surabaya di kelas 9F pada tahun akademik 
2020/2021. Oleh karenanya diperlukan adanya analisis efektivitas keberhasilan penggunaan platform Microsofts Teams yang digunakan sebagai platform pembelajaran selama pandemic Covid-19.

\section{METODE}

Penelitian ini merupakan penelitian kuantitatif. Penelitian kuantitatif adalah penelitian pengambilan data berupa angka yang dianalisis dalam bentuk statistik secara kuantitatif Penelitian ini bertujuan untuk menganalisis efektivitas penggunaan Microsofts Teams (X1) terhadap hasil belajar (Y). Populasi dalam penelitian ini adalah yang berjumlah 40. Teknik sampling yang digunakan adalah sampel jenuh sebab semua anggota populasi yang digunakan sebagai sampel. Dalam penelitian ini sampel yang digunakan dibawah 100 maka dari itu teknik sampel yang digunakan sampel jenuh. Karena keterbatasan waktu dan tenaga maka peneliti menggunakan sampel jenuh.

Data hasil belajar dalam penelitian ini menggunakan nilai penilaian akhir tahun (PAT) semester genap tahun 2020/2021. Indikator yang digunakan untuk mengukur efektifitas penggunaan
Microsofts Teams meliputi kemudahan dalam mengakses platform Microsofts Teams, pemahaman materi dalam pembelajaran dengan menggunakan Microsofts Teams, keunggulan penggunaan aplikasi Microsofts Teams dalam pembelajaran daring. Sebelum instrumen tersebut digunakan terlebih dahulu dilakukan uji validitas dan realibilitas instrumen. Valid tidaknya suatu instrumen dalam penelitian ini dilihat berdasarkan nilai person product moment pada hasil pengujian, sedangkan reliabel atau tidaknya suatu instrumen dari penelitian ini dihitung berdasarkan nilai Cronbach Alpha berdasarkan data hasil pengujian.

\section{HASIL DAN PEMBAHASAN}

Hasil analisis deskriptif pada variabel efektivitas penggunaan Microsoft Teams disajikan pada tabel 1. Berdasarkan data pada tabel 1 diperoleh informasi bahwa ketiga indikator berada pada kategori baik. Pada indikator pertama yaitu kemudahan dalam mengakses platform Microsoft Teams diperoleh hasil nilai presentasi sebesar 80.5 yang tergolong kategori baik. hal ini menunjukkan bahwa platform Microsoft Teams sangat mudah untuk digunakan pada saat pembelajaran. 
Tabel 1. Presentase Efektivitas Penggunaan Microsoft Teams

\begin{tabular}{|c|c|c|c|c|}
\hline No & Indikator & Mean & $\%$ & Kategori \\
\hline 1 & $\begin{array}{l}\text { Kemudahan } \\
\text { dalam } \\
\text { mengakses } \\
\text { aplikasi } \\
\text { Microsoft } \\
\text { Teams }\end{array}$ & 3.90 & 80.5 & Baik \\
\hline 2 & $\begin{array}{l}\text { Pemahaman } \\
\text { materi } \\
\text { pembelajaran } \\
\text { dengan } \\
\text { menggunakan } \\
\text { Microsoft } \\
\text { Teams }\end{array}$ & 3.85 & 82 & Baik \\
\hline 3 & $\begin{array}{l}\text { Keunggulan } \\
\text { penggunaan } \\
\text { aplikasi } \\
\text { Microsoft } \\
\text { Teams }\end{array}$ & 3.80 & 78 & Baik \\
\hline & Rata-rata & 3.85 & 80.16 & Baik \\
\hline
\end{tabular}

Pada indikator kedua, yaitu pemahaman materi pembelajaran dengan menggunakan platform Microsoft Teams diperoleh nilai presentasi sebesar 82 yang tergolong kategori baik. Dengan begitu platform pembelajaran Microsoft Teams dapat dikatakan memberikan kemudahan dalam memahami materi peserta didik. Sedangkan untuk indikator ketiga, yaitu keunggulaan penggunaan platform Microsoft Teams diperoleh hasil nilai presentasi sebesar 78 dan tergolong kategori baik. Dengan begitu platform pembelajaran Microsoft Teams dikatakan efektif digunakan pada saat pembelajarn daring di SMP Negeri 44 Surabaya.
Efektifitas penggunaan Microsoft Teams diukur dari 3 indikator, yaitu 1). kemudahan dalam mengakses platform Microsoft Teams, penggunaan platform Microsoft Teams ini sangat mudah karena dapat dengan cepat dalam mengunggah atau mendownload file tugas yang diberikan oleh guru, fitur dalam platform Microsoft Teams juga sangat mudah untuk diakses meskipun diakses oleh banyak peserta didik, sehingga peserta didik tidak mengalami kesulitan dalam pembelajaran menggunakan Platform Microsoft Teams (Karthikeyan, 2020). 2). Pemahaman materi pembelajaran dengan menggunakan Microsoft Teams, ketika pembelajaran menggunakan platform Microsoft Teams guru dapat melakukan share PowerPoint (PPT) pada saat ketika menjelaskan materi sehingga memudahkan peserta didik dalam memahami materi. Diana, (2020) yang menyimpulkan bahwa proses pembelajaran dengan menggunakan microsoft teams memudahkan peserta didik dalam memahami materi. 3). Keunggulan penggunaan aplikasi microsoft teams menurut (Widiyarso \& Sutama, 2021) platform microsoft teams mudah diakses meskipun dengan kecepatan internet yang rendah, dapat 
digunakan dimanapun dan kapanpun, dan sudah terintegrasi dengan Microsoft Office.

Hasil dari data diatas bahwa efektifitas penggunaan Microsoft Teams dapat terlihat pada penggunaannya dan ditinjau dari tiga indikator, yaitu kemudahan dalam mengakses platform Microsoft Teams, pemahaman tentang materi pembelajaran dengan menggunakan platform Microsoft Teams, dan keunggulan yang dimiliki oleh platform Microsoft Teams. Berdasarkan hasil dari penelitian yang sudah dilakukan besar rata-rata presentasi pencapaian sebesar $80.16 \%$ dengan hasil penyebaran kuisioner sebesar 3.85 yang tergolong kategori jawaban baik. Hasil tersebut menunjukkan bahwa penggunaan platform Microsoft Teams efektif digunakan pada pembelajaran. Peserta didik dapat lebih aktif dan kreatif saat melaksanakan pembelajaran karena menurut (Situmorang, 2020) respon positif dan minat belajar yang tinggi pada platform Microsoft Teams.

Dapat disimpulkan bahwa platform Microsoft Teams efektif digunakan dalam proses pembelajaran Ilmu Pengetahuan Alam (IPA) di SMP Negeri 44 Surabaya pada kelas 9F tahun akademik 2020/2021. Karena pada masa pembelajaran daring dibutuhkan platform yang mudah untuk digunakan agar proses pembelajaran dapat terlaksana dengan baik. Di samping itu hubungan antara platform Microsoft Teams dan hasil belajar memiliki arah yang positif Seperti penelitian (Situmorang, 2020) bahwa penggunaan microsoft teams terus meningkatkan minat pembelajaran sehingga hasil pembelajaran juga tetap bagus dan pembelajaran dalam masa daring akan lebih baik.

\section{SIMPULAN}

Hasil penelitian ini dapat disimpulkan bahwa efektivitas penggunaan Microsoft Teams dalam pembelajaran berada pada kategori baik pada indikator pertama yaitu kemudahan dalam mengakses platform Microsoft Teams diperoleh hasil nilai presentasi sebesar 80.5 yang tergolong kategori baik, Pada indikator kedua yaitu pemahaman materi pembelajaran dengan menggunakan platform Microsoft Teams diperoleh nilai presentasi sebesar 82 yang tergolong kategori baik, dan indikator ketiga, yaitu keunggulaan penggunaan platform diperoleh hasil nilai presentasi sebesar 78 dan tergolong kategori baik. 
Ketiga indicator diperoleh nilai presentasi $80.16 \%$.

Saran yang dapat disampaikan berdasarkan hasil penelitian ini, yaitu: 1) dengan adanya penggunaan e-learning dengan Microsoft Teams, guru-guru diharapkan mampu merangsang siswa dengan berbagai model atau metode pembelajaran yang ada, seperti pemberian dan pengumpulan tugas yang tersistem, sehingga dalam melaksanakan pembelajaran siswa tidak merasa bosan dan jenuh selama mengikuti kegiatan pembelajaran secara daring; 2) kepada peneliti berikutnya sangat dianjurkan agar menambahkan variabel lainnya dengan menggunakan penelitian yang serupa dan menggunakan metode atau pendekatan yang lain, seperti pengembangan model pembelajaran dengan menggunakan platform Microsoft Teams pada subjek yang lebih luas.

\section{DAFTAR PUSTAKA}

Arikunto, S. (2010). Prosedur Metedologi Penelitian: Suatu Pendekatan Praktis. Penerbit Rineka Cipta.
Arsyad, Azhar. (2003). Media Pembelajaran. Jakarta: PT Raja Grafindo Persada.

Borba, M. C., Askar, P., Engelbrecht, J., Gadanidis, G., Llinares, S., \& Aguilar, M. S. (2016). Blended Learning, E-learning and Mobile Learning in Mathematics Education. ZDM, 48(5), 589-610. https://doi.org/10.1007/s11858-160798-4.

Chandrawati, S. R., (2010). Pemanfaatan E-learning dalam Pembelajaran. $\begin{array}{llll}\text { No } & 2 & \text { Vol. } & 8 \text {. }\end{array}$ http://jurnal.untan.ac.id/.

Diana, R. (2020). Implementasi Model Poe2we Dalam Lks Materi Elastisitas Bahan Dengan Menggunakan Microsoft Teams Untuk Meningkatkan Kualitas Pembelajaran Fisika. https://Doi.Org/10.31219/Osf.Io/8 ket4.

Gunawan, G., Suranti, N. M. Y., \& Fathoroni, F. (2020). Variations of Models and Learning Platforms for Prospective Teachers During the COVID-19 Pandemic Period. 
Indonesian Journal of Teacher

Education 1(2):61-70.

Maisyarah, R., Purwaningsih, E., \& Buwono, S. (2014). Efektivitas Penerapan Aplikasi Microsoft Office Pada Pembelajaran Akuntansi Di Kelas X Smk. 1-12.

Rahayu, F. (2019). Pengaruh Konsep Diri dan Disiplin Belajar terhadap Motivasi Belajar Peserta Didik di Sekolah Menengah Pertama Negeri 4 Palu pada Mata Pelajaran Pendidikan Agama Islam. Paedagogia: Jurnal Pendidikan. 8 (2): 113-138. https://doi.org/10.24239/pdg.vol8.i $\underline{\mathrm{ss} 2.45 .}$.

Ridwan, T. \& Umam, A.F. (2020). Pengaruh Media Pembelajaran Google Classroom dalam Pembelajaran terhadap Motivasi Belajar Mahasiswa. Jurnal Ilmiah Indonesia. 1 (1): 37-46.

Rikizaputra \& Sulastri, H. (2020). Pengaruh E-learning dengan Google Classroom terhadap Hasil dan Motivasi Belajar Biologi Siswa. Lectura: Jurnal Pendidikan. 11 (1): 106-118. https://doi.org/10.2183/tja.75.1_27

Widiyarso, T. H., \& Sutama. (2021). Efektifitas Penggunaan Microsoft Teams Dalam Pembelajaran ELearning Bagi Guru Selama Pandemi Covid-19. Jurnal Pendidikan dan Ilmu Pengetahuan, 21(1), 15-21. 